\title{
Cyberbullying among Saudi's Higher-Education Students: Implications for Educators and Policymakers
}

\author{
Abdulrahman M Al-Zahrani ${ }^{1,2, *}$ \\ ${ }^{1}$ Faculty of Education, King Abdulaziz University, Jeddah, Saudi Arabia \\ ${ }^{2}$ Faculty of Education, Univsersity of Jeddah, Jeddah, Saudi Arabia \\ *Correspondence: Faculty of Education, Univsersity of Jeddah, Jeddah, Saudi Arabia. Tel: 966-544-805-570. E-mail: \\ ammz2@hotmail.com; ammzahrani@kau.edu.sa
}

Received: January 11, 2015

Accepted: February 2, 2015 Online Published: April 29, 2015

doi:10.5430/wje.v5n3p15

URL: http://dx.doi.org/10.5430/wje.v5n3p15

\begin{abstract}
The aim of the current study was to investigate cyberbullying among Saudi's higher-education students. It also aimed to identify possible factors that may impact cyberbullying. A quantitative approach was implemented using an online survey questionnaire distributed to 287 students. The descriptive results indicated that students mainly avoid cyberbullying. However, about $27 \%$ of the students reported that they have committed cyberbullying at least once or twice. Furthermore, $57 \%$ of the students observed at least one student being cyberbullied. Students encounter cyberbullying usually by people whom they do not know and who contacted them over the Internet. In addition, students perceive cyberbullying as a serious issue. Thus, students seem to prefer asking cyberbullies to stop, but avoiding fighting back. Gender was found to impact on how often did students commit cyberbullying. Male students were involved in cyberbullying more than female students. In addition, single students more than married students encounter cyberbullying by people they know. Finally, students who access the Internet via personal devices observe cyberbullying more than those using shared devices. Based on this, implications were analyzed and suggested were proposed in relation to policy and practice.
\end{abstract}

Keywords: cyberbullying; ICT; higher education; policymakers; Saudi Arabia

\section{Introduction}

\subsection{Introducing the Problem}

Information and Communication Technology (ICT) has introduced new atmospheres for communication and learning. However, this seems optimistic and only shows part of the equation. Evidence shows that ICT can be harmful (Cowie \& Colliety, 2010). Given the rapid increases in Internet use by teenagers along with the inadequate supervision from adults, there is a good reason for concern (Cowie \& Colliety, 2010; Hinduja \& Patchin, 2010; Gross \& Juvonen, 2008; Hoff \& Mitchell, 2009; Smith \& Yoon, 2012). When teenagers spend a large amount of time on the Internet, potentials for misuse and harm can also increase (Hinduja \& Patchin, 2010; Smith \& Yoon, 2012; Tettegah, Betout \& Taylor, 2006). Bearing this in mind, "the digital world is an enormous and somewhat interminable platform for individuals to abuse others" (Akbulut \& Eristi, 2011: 1156).

\subsection{Cyberbullying}

A possible consequence of the inappropriate use of ICT is cyberbullying. Couvillon and Ilieva (2011) consider cyberbullying as a negative result of the wide expansion of ICT use such as social networks and mobile devices among teenagers. In consequence, cyberbullying is a "major public health concern facing youth" in the digital era (Gross \& Juvonen, 2008: p. 497).

Cyberbullying can be known as electronic bullying, digital bullying, cyber harassment (Hinduja \& Patchin, 2009), digital aggression (Wong-Lo \& Bullock, 2011), cyber-stalking, and cyber-abuse (Grigg, 2012). For a behavior to be deemed cyberbullying, it should be intentionally harmful, repetitive, lack power balance, and transmitted electronically (The Department of Education and Early Childhood Development, 2013; Vandebosch \& Van Cleemput, 2008; Smith \& Yoon, 2012). Smith et al. (2008) define cyberbullying as "an aggressive, intentional act 
carried out by a group or individual, using electronic forms of contact, repeatedly and over time against a victim who cannot easily defend him or herself" (p. 376). Another view was provided by Bullying Statistics (2013), which illustrated that "Cyber bullying involves using technology, like cellphones and the Internet, to bully or harass another person". As such "the ramification of cyberbullying occurs through unconventional strategies (e.g., text messaging, online Web logs, video sharing)" (Wong-Lo \& Bullock, 2011: 64).

Based on this, the cyberbully is the individual who deliberately uses ICT to harm a person or a group of people (Ahlfors, 2010). With the wide expansion of the Internet use, it is easier for cyberbullies to target students who usually find it difficult to avoid (Atkins \& Newton, 2010; Couvillian \& Ilieva, 2012; Hinduja \& Patchin, 2010; Tettegah et al., 2006; The Department of Education and Early Childhood Development, 2013). Regarding this, Tettegah et al. (2006) explained that "Before the Internet children were able to escape their bullies by going home to the safety of their family, but with the emergence of cyber-bullying children have no place to escape" (p. 20). This can be supported by the notion that "There is also the ease of adopting another identity. Thus, the victim may not know who the perpetrator is" (Grigg, 2012: 203). Akbulut and Eristi (2011) emphasized that "Anonymous users of different age groups attack victims of any age. Thus, cyberbullying and victimization are not peculiar to a certain age group" (1156). In addition, "the effects of this digital form of peer aggression can be as detrimental as face-to-face bullying" (Wong-Lo \& Bullock, 2011: 64).

Cyberbullying is a real risk to students and may cause both emotional and physical harm (Akbulut \& Eristi, 2011; Gross \& Juvonen, 2008; Smith \& Yoon, 2012; The Department of Education and Early Childhood Development, 2013). It may also hinder the academic development of learners (Akbulut \& Eristi, 2011; Tettegah et al., 2006; The Department of Education and Early Childhood Development, 2013). Other consequences may include "post-traumatic stress disorder, substance abuse, social, and personal relationship problems" (Tettegah et al., 2006: 21). More seriously, cyberbullying may cause students to have suicidal thoughts and attempt suicide more than those who did not experience such forms of cyber harassment (Hinduja \& Patchin, 2010).

\subsection{Bullying versus Cyberbullying}

A growing trend of research takes into account facets of similarities and differences between conventional bullying and cyberbullying. This is to understand the nature of bullying and how it differs when technology is involved. In this regard, Vandebosch and Van Cleemput (2009) argue that "Transferring the characteristics of traditional bullying to bullying via electronic communication tools is more difficult than it appears" (p. 1351). On the one hand, however, some scholars call for treating cyberbullying as an emerging global problem rather than a development of conventional bullying. For example, Grigg (2012) states that "Emerging theory indicates the need to treat cyber-bullying as a standalone entity without the confounding role that the more traditional concept of bullying plays in cyber bullying definitions" (p. 202).

On the other hand, Cowie and Colliety (2010) argue that "cyberbullying is often an extension of real-world bullying" (p. 266). The Department of Education and Early Childhood Development (2013) in Victoria State, Australia characterized cyberbullying as a type of bullying among verbal or written abuse, violence, sexual harassment, homophobia, and discrimination. The department also illustrated the types of cyberbullying, which include pranking, unflattering or private images sharing or sexually explicit images, sending insulting or threatening text and email, publishing embarrassing personal online information, identity theft, and hate sites. Analyzing the contextual differences between traditional bullying and cyberbullying, Vandebosch and Van Cleemput (2009) introduced a significant work in this area (see Table 1): 
Table 1. Types of Cyberbullying

\begin{tabular}{|c|c|}
\hline Traditional Bullying & Cyberbullying \\
\hline $\begin{array}{l}\text { Direct bullying } \\
\text { Physical (e.g., hitting): } \\
\text { - Property (e.g., damaging someone's personal } \\
\text { - belongings) } \\
\text { - Verbal (e.g., calling someone names) } \\
\text { - } \quad \text { Son-verbal (e.g., making obscene gestures) } \\
\text { (e.g., excluding someone from a group) }\end{array}$ & $\begin{array}{l}\text { Direct bullying } \\
\text { Physical: } \\
\text { - } \\
\text { Property (e.g., purposely sending a virus } \\
\text { infected file) } \\
\text { - Verbal (e.g., using the Internet or mobile } \\
\text { phone to insult or threaten) } \\
\text { - Non-verbal (e.g., sending threatening or } \\
\text { obscene pictures or illustrations) } \\
\text { - Social (e.g., excluding someone from an } \\
\quad \text { online group) }\end{array}$ \\
\hline $\begin{array}{l}\text { Indirect bullying } \\
\text { (e.g., spreading false rumors) }\end{array}$ & $\begin{array}{l}\text { Indirect bullying } \\
\text { - 'Outing' of email entrusted information } \\
\text { masquerading, e.g., deceiving someone by } \\
\text { pretending to be someone else } \\
\text { - Spreading gossip by mobile phone, email or } \\
\text { chat } \\
\text { - Taking part in voting on a defamatory polling } \\
\text { website }\end{array}$ \\
\hline
\end{tabular}

\subsection{Alarming Statistics}

Cyberbullying becomes a global concern because it reaches alarming levels. For instance, Reuters News sponsored an intensive global cyberbullying survey in 2012. The survey polled 18,000 people living in 24 countries including Argentina, Australia, Belgium, Brazil, Canada, China, France, Germany, Great Britain, Hungary, India, Indonesia, Italy, Japan, Mexico, Poland, Russia, Saudi Arabia, South Africa, South Korea, Spain, Sweden, Turkey, and the USA. Results show that $80 \%$ of the participants acknowledged cyberbullying as a serious problem. Based on the responses of 6,500 parents, the most widely reported tool for cyberbullying was social networking sites with about $60 \%$. This is followed by mobile devices and online chat rooms with about $40 \%$ for each. India had one of the highest rates of cyberbullying, with $32 \%$ of parents reporting that their children had experienced cyberbullying. This is followed by Brazil with 20\%, both Canada and Saudi Arabia with $18 \%$ and 15\% in the USA (Reuters, 2012).

In a study conducted by Gross and Juvonen (2008), 1,454 students from across the USA participated in a cyberbullying survey published in a teen website. Results approved a positive relationship between the extensive use of the Internet and cyberbullying. In addition, the results showed that about $72 \%$ of the students have encountered cyberbullying at least once during the last year, and interestingly, did not inform their parents due to fears of restricting their Internet use. In another study conducted by Hoff and Mitchell (2009), the pervasiveness and causes of cyberbullying, the psychological impact on students, and the responses to cyberbullying from students and administrators were investigated. The authors implemented a qualitative/quantitative design to collect data from 351 students. They found that cyberbullying is most likely to occur from relationship problems such as break-ups, envy, intolerance, and ganging up. Based on this, cybervictims experience negative psychological impacts related to their well-being. Interestingly, schools and students reactions toward cyberbullying were found to be absent or ineffective and based on avoidance strategy in general, whether from students, parents or schools.

With respect to higher education, Smith and Yoon (2012) conducted a study on cyberbullying in universities in the USA. Researchers implemented an online survey and interview methodology to gather data from 276 students. Results confirmed that students as well as instructors had experienced cyberbullying. However, the majority of participants did not consider cyberbullying as a problem at the university level. On the other hand, cyberbullied students reported moderate to extreme impacts of cyberbullying on their life and learning including physical endangerment. In a relatively similar context to Saudi Arabia, a study was conducted to investigate the extent of cyberbullying and victimization among 254 Turkish university students by Akbulut and Eristi (2011). Their study findings revealed that male students were more likely to be both cybervictims and cyberbullies. They also found that both cyberbullying and victimization stances were not associated with age, college course', daily average use of the Internet, language proficiency, socioeconomic status, and the place where the Internet was accessed. 


\subsection{Confronting Cyberbullying}

Cyberbullying is a real global problem that should be confronted. In this regard, Sellers, Wray, Meeker and Moulton (2009) stated that "The rates of cyberbullying that have been discovered so far in the academic literature demonstrate the mere pervasiveness of the problem is a cause for concern" (p. 2299). For this, most scholars interested in studying the effects of cyberbullying agree that education plays a vital role in addressing the problem (Akbulut \& Eristi, 2011; Atkinson \& Newton, 2010; Burnham, Inman, Ogorchock, \& Wright, 2009; Cowie \& Colliety, 2010; Gross \& Juvonen, 2008; Hinduja, \& Patchin, 2011, 2010; Hoff \& Mitchell, 2009; Kowalski, Limber \& Agatston, 2012; Shariff, 2005; Sellers et al., 2009; Smith \& Yoon, 2012; Tettegah et al., 2006; Wong-Lo \& Bullock, 2011).

According to Hinduja and Patchin (2011), cyberbullying is a crucial issue facing educators and whether "school officials have the right to restrict student expressions or to discipline students for behavior or speech deemed inappropriate" (p. 72). Wong-Lo \& Bullock (2011) suggested that "a proactive approach in collaborating and educating parents, school personnel, and citizens in the communities about cyberbullying is one step toward prevention of this evolving issue" (p. 69). Similarly, "schools also have a critical role to play in preventing and reducing cyberbullying through a process of awareness-raising, the education of the emotions and active participation of children and young people themselves" (Cowie \& Colliety, 2010: 261). From another perspective, universities have responsibilities in confronting and preventing cyberbullying including policymakers, administrators, and staff to monitor electronic resources and providing reporting tools for students (Smith \& Yoon, 2012). However, "While educators need to be aware that cyber-bullying is covert and difficult to identify, likewise, administrators need to be careful not to fall into the current trend of taking a defensive stance in dealing with individual cases of cyber-bullying" (Tettegah et al., 2006: 22-23). Regarding law enforcement, "It is vital that educators not only be aware of these laws, but also know how they are to be implemented in the school setting." (Tettegah et al., 2006: 23).

In practical terms, Hoff and Mitchell (2009) proposed "three-pronged approach" (p. 662) for dealing with cyberbullying. This approach involves (a) educating students, educators, and parents on the risks of virtual spaces and teach them the appropriate ways to protect students, (b) expanding schools' approaches toward cyberbullying by teaching students how to deal with the daily social tensions and problems, and (c) addressing legal cases related to cyberbullying and discussing interventions and possible solutions through professional networks such as conferences and professional associations. As such, Kowalski et al. (2012) provide a nine-element guide for responding to cyberbullying as follows:

1. Save or print copies of nasty messages and websites as evidence.

2. Ignore, delete, or block the sender if it was a one-time offense.

3. Report fake or offensive profiles to the site host.

4. Investigate and monitor children's online activities.

5. Communicate with the school personnel and share evidence if the cyberbully is a student.

6. Contact the cyberbully's guardians and share evidence if he is known.

7. Seek legal advice if the cyberbully's guardians are unresponsive.

8. Report the cyberbullying to the police.

9. Seek help from a school counselor or other mental health professional, if your child expresses emotional problems.

\section{Research Problem, Aim, Scope, and Questions}

Although cyberbullying reaches alarming levels globally, it has received little attention in developing countries, such as Saudi Arabia, especially from the education perspective. Thus, addressing the problem in Saudi Arabia is necessary and may inform the research context in this area. Furthermore, research on cyberbullying is still beyond satisfaction because much of it focuses on adolescents (Akbulut \& Eristi, 2011; Kowalski et al., 2012; Smith \& Yoon, 2012). Accordingly, "Future research needs to examine preventative solutions for cyber-bullying and cyber-aggression” (Grigg, 2012).

The aim of the current study, therefore, is to investigate cyberbullying among Saudi's higher-education students. In addition, the aim is to identify possible factors that may impact cyberbullying such as gender, type of property, type of room, marital status, Internet access, and academic performance. The key research questions are given below:

1. How often did students bully other students online? 
2. How often did students see a student or group of students bully other students online?

3. If a student was bullied by others, who did it?

4. How well did bullied students know the person or the group of people who bullied them?

5. How do students feel about cyberbullying?

6. What are the best ways to stop students from bullying others online?

7. Do demographic information including gender, type of property, type of room, marital status, Internet access, and academic performance impact cyberbullying?

\section{Methodology}

To answer the research questions, a quantitative approach was implemented using a survey questionnaire. Quantitative approach can be defined as a systematic investigation of a social phenomenon via statistical techniques (Mertens, 2005).

\subsection{Questionnaire Design}

The survey design included two major sections: (a) general information and (b) cyberbullying scale, which is a modified version of Cross et al. (2009). The first section studies the students' gender, type of home, marital status, type of room, Internet access, and academic performance. The second section reports on issues relevant to cyberbullying such as how often students did bully other students online. Other questions included: How often did you see a student or group of students bully other students online? If a student was bullied by others, who did it? How well did bullied students know the person or the group of people who bullied them? How do students feel about cyberbullying? Lastly, what are the best ways to stop students from bullying others online?

\subsection{Sampling}

The strategy used in the current study is probability sampling in which there is a possibility for every member of the population to participate (Mertens, 2005). Probable sampling strategy aims at allowing a random, but convenient sample to participate (Mertens, 2005).

More than 300 students (20 - 23 years old) participated in the current study from The Faculty of Education at King Abdulaziz University using online survey that was distributed via social networking tools such as Twitter and Facebook. The online survey was built using Google Forms to allow participants to easily access the survey review and edit their responses. It also provides them with more flexibility regarding time and the tool used to respond such as computers or handheld devices. After the deadline to fill in the online questionnaires, incomplete surveys were excluded. The final number of useable surveys was 287 copies.

\subsection{Validity and Reliability}

The vast majority of the participants speak the Arabic language. Therefore, the questionnaire was first developed in English and subsequently translated into Arabic before distribution. It is important to ensure that the participants feel very comfortable in reading and responding to the questions to obtain comprehensive answers from them. As the Arabic language is the researcher's mother tongue, the researcher translated the questionnaire to ensure its accuracy. According to Mertens (2005), 'because survey research uses decontextualized words through its very nature, the researcher must be careful to interpret the words in light of the particular cultural circumstances' (p. 185). Hence, three specialists and Arabic native speakers reviewed the translations to ensure its accuracy and clarity.

Questionnaire validity was tested using a panel of experts to check its relevance, content, and construct (Mertens, 2005). Based on the experts' opinions, necessary and appropriate changes were made. Reliability statistics was conducted using Cronbach's alpha coefficient and the acceptable level of internal consistency was indicated. Cronbach's alpha coefficient scored .7 (Pallant, 2007).

\section{Results}

\subsection{Descriptive Results}

Table 2 shows that more female students (with about 54\%) participated compared with male students. Furthermore, most of the students (70\%) live in family-owned houses, are single (64\%), and have their own private room (54\%). The vast majority of the students $(92 \%)$ have their own devices to access the Internet. Finally, $57 \%$ of the students 
reported that their academic performances are about the same as most other students in their year level. Only a few number of students $(n=5)$ reported that they were not as good as most other students in their year level.

Table 2. Participants' Information

\begin{tabular}{llll}
\hline & Group & $\mathrm{N}$ & $\%$ \\
\hline Gender & Male & 133 & 46.3 \\
& Female & 154 & 53.7 \\
Type of House & Rented house & 95 & 33.1 \\
& Own a house & 192 & 66.9 \\
Marital Status & Single & 184 & 64.1 \\
& Married & 103 & 35.9 \\
Type of Room & Shared room & 132 & 46.0 \\
& Private room & 155 & 54.0 \\
Internet Access & Shared Device & 24 & 8.4 \\
& Own a device & 263 & 91.6 \\
academic performance & Not as good as most other students in my year level & 5 & 1.7 \\
& About the same as most other students in my year level & 165 & 57.5 \\
& Better than most other students in my year level & 117 & 40.8 \\
\hline
\end{tabular}

\subsection{Prevalence of Cyberbullying}

Results indicated that students mainly avoid bullying other students online (73.5\%). However, 76 students (26.5\%) reported that they have bullied other students online once or twice. See Table 3.

Table 3. How Often Did You Bully Another Student or Group of Students Online?

\begin{tabular}{lll}
\hline Group & $\mathrm{N}$ & $\%$ \\
\hline I did not bully other students online & 211 & 73.5 \\
I bullied other students this way once or twice & 76 & 26.5 \\
\hline
\end{tabular}

\subsection{Observing Cyberbullying}

Table 4 shows that most of the students (57\%) have observed at least one student being bullied online at least once or twice.

Table 4. How Often Did You See Students Bully Others In Ways That Can't Be Easily Seen By Others?

\begin{tabular}{lll}
\hline Group & $\mathrm{N}$ & $\%$ \\
\hline I saw at least one student being bullied this way once or twice & 163 & 56.8 \\
I did not see other students being bullied this way & 85 & 29.6 \\
I saw at least one student being bullied this way about once a week & 35 & 12.2 \\
I saw at least one student being bullied this way most days & 4 & 1.4 \\
\hline
\end{tabular}

\subsection{Gender and Cyberbullying}

To record the students' responses, a three-point scale was used $(1=$ No, $2=$ Sometimes, and $3=$ Always $)$. Table 5 shows that most cyberbullying is committed by male students $(M=1.67, S D=.77)$.

Table 5. If a Student Was Bullied by Others, Who Did It?

\begin{tabular}{lll}
\hline Groups & $M$ & $S D$ \\
\hline Mainly one boy & 1.67 & .77 \\
Mainly one girl & 1.46 & .54 \\
A group of girls & 1.37 & .62 \\
Both boys and girls & 1.31 & .48 \\
A group of boys & 1.23 & .48 \\
\hline
\end{tabular}




\subsection{Relationship with Cyberbullies}

Using the three-point scale ( 1 = No to $3=$ Always), Table 6 shows that students were bullied online by someone or people they do not know and who contacted them over the Internet $(M=1.76, S D=.72)$. In addition, it is unlikely for students to be bullied online by people whom they met over the Internet $(M=1.40, S D=.51)$ or by people who know in reality $(M=1.32, S D=.47)$.

Table 6. How well did bullied students know the person or the group of people who bullied them?

\begin{tabular}{lll}
\hline Groups & $M$ & $S D$ \\
\hline I was bullied online by someone or people I don't know, who contacted me over the Internet & 1.76 & .72 \\
I was bullied online by someone or people who I met over the Internet & 1.40 & .51 \\
I was bullied online by someone or people I know & 1.32 & .47 \\
\hline
\end{tabular}

\subsection{Students’ Views about Cyberbullying}

Students' attitudes toward cyberbullying are shown in Table 7. Using the three-point scale, results show that students perceive cyberbullying as a serious issue based on the total sum of their responses $(M=2.02, S D=.38)$. In addition, all the items fall in the range of sometimes (i.e., 2).

Table 7. How do students feel about cyberbullying?

\begin{tabular}{lll}
\hline Items & $M$ & $S D$ \\
\hline Students shouldn't be allowed to say whatever they want about other students on their personal & 2.43 & .66 \\
web pages (e.g., Twitter, Facebook) [Reversed] & & \\
It is easier to bully another student over the Internet than in person & 2.31 & .74 \\
Electronic bullying is scarier than face-to-face bullying & 2.06 & .79 \\
It is more hurtful to bully other students over the Internet than in person & 1.86 & .71 \\
If you report electronic bullying, you will be the next one to be bullied & 1.81 & .79 \\
Websites that make fun of other students are not funny & 1.66 & .78 \\
Total Attitude & 2.02 & .38 \\
\hline
\end{tabular}

\subsection{Confronting Cyberbullying}

According to the three-point scale used, fighting back $(M=1.51, S D=.73)$ and considering cyberbullying as a joke ( $M$ $=1.51, S D=.61)$ did not agree well among or were not supported by students. Students seem to prefer asking online bullies to stop $(M=2.25, S D=.76)$ and keeping a record of nasty emails or text messages $(M=2.23, S D=.80)$. However, most of the items fall in the range of sometimes (i.e., 2). This indicates that the students have no clear response to cyberbullying. The suggested solutions are sorted inTable 8 from the highest agreement to the lowest.

Table 8. What Are the Best Ways to Stop Students from Bullying Others Online?

\begin{tabular}{lll}
\hline Items & $M$ & $S D$ \\
\hline Asking them to stop & 2.25 & .76 \\
Keeping a record of nasty emails or text messages (SMS) & 2.23 & .80 \\
I did not respond to the threatening or nasty emails or other electronic messages & 2.18 & .80 \\
I asked for help from someone I trust such as a friend, family member or staff & 2.17 & .73 \\
Reporting to police or other authorities & 2.14 & .79 \\
I stayed away from the person bullying me or the website where it occurred & 2.11 & .79 \\
Ignoring it & 2.08 & .79 \\
I asked for help from a website & 1.76 & .75 \\
Changing email address or mobile phone number & 1.76 & .78 \\
I turned off my computer or mobile phone, or blocked messages or profiles & 1.62 & .71 \\
I made a joke of it & 1.51 & .61 \\
Fighting back & 1.51 & .73 \\
\hline
\end{tabular}




\subsection{Further Statistics on Cyberbullying}

A one-way between-groups multivariate analysis of variance (MANOVA) was performed to investigate the impact of the students' gender, type of property, type of room, marital status, Internet access, and academic performance, as independent variables. On how often students bullied other students online, the following were the dependent variables: How often did you see a student or group of students bully other students online? If a student was bullied by others, who did it? How well did bullied students know the person or the group of people who bullied them?

Preliminary assumption testing was conducted to check the sample distribution, linearity, and normality, with some violations noted (Pallant, 2007). Firstly, Box's Test of Equality of Covariance Matrices shown in Table 9 reveals that the data violate the assumption of homogeneity of variance covariance matrices (significant value is less than .001).

Table 9. Box's Test

\begin{tabular}{ll}
\hline Box's M & 313.720 \\
\hline F & 4.957 \\
df 1 & 55 \\
df 2 & 15832.001 \\
Sig. & .000 \\
\hline
\end{tabular}

Secondly, According to Levene's Test of Equality of Error Variances, the significance values of the independent variables were less than .05 . This indicates that the data have violated the assumption of equality of variance (see Table 10).

Table 10. Levene's Test of Equality of Error Variances

\begin{tabular}{|c|c|c|c|c|}
\hline Dependent Variables & $\mathrm{F}$ & df1 & $\mathrm{df} 2$ & Sig. \\
\hline How often did you bully another student or group of students & 11.98 & 31 & 255 & .000 \\
\hline I was bullied in these ways by someone or people I know & 7.29 & 31 & 255 & .000 \\
\hline $\begin{array}{l}\text { I was bullied in these ways by someone or people I don't know, who contacted } \\
\text { me over the Internet }\end{array}$ & 6.97 & 31 & 255 & .000 \\
\hline I was bullied in these ways by someone or people whom I met over the Internet & 19.58 & 31 & 255 & .000 \\
\hline How often did you see a student or students bully others on line? & 5.19 & 31 & 255 & .000 \\
\hline Mainly one boy & 6.52 & 31 & 255 & .000 \\
\hline A group of boys & 3.48 & 31 & 255 & .000 \\
\hline Mainly one girl & 15.09 & 31 & 255 & .000 \\
\hline A group of girls & 5.286 & 31 & 255 & .000 \\
\hline Both boys and girls & 7.536 & 31 & 255 & .000 \\
\hline
\end{tabular}

Accordingly, Pallant (2007) suggests a more conservative alpha level for determining significance for the variables in the univariate. Tabachnick and Fidell (2001) recommend an alpha value of .025 or .01 , rather than .05 . In the current study, the alpha value of .01 was used to enhance the credibility of the analysis. Furthermore, instead of reporting the value of Wilks' Lambda, Pillai's trace value can be more robust (see Table 11).

Table 11. Multivariate Tests

\begin{tabular}{|c|c|c|c|c|c|c|c|}
\hline Effect & & Value & $\mathrm{F}$ & Hypothesis df & Error df & Sig. & $\begin{array}{l}\text { Partial Eta } \\
\text { Squared }\left(\eta^{2}\right)\end{array}$ \\
\hline Gender & Pillai's Trace & .18 & 5.22 & 10 & 246 & .000 & .18 \\
\hline Status & Pillai's Trace & .15 & 4.20 & 10 & 246 & .000 & .15 \\
\hline Internet Access & Pillai's Trace & .13 & 3.58 & 10 & 246 & .000 & .13 \\
\hline
\end{tabular}

Table 11 above indicates that some independent variables impact on the dependent variables as follows:

1. $\operatorname{Gender}\left[F(10,246)=3.38, p=.000\right.$; Pillai's Trace $=.18$; partial $\left.\eta^{2}=.18\right]$.

2. Marital status $\left[F(10,246)=3.39, p=.000 ;\right.$ Pillai's Trace $=.15$; partial $\left.\eta^{2}=.15\right]$.

3. Internet Access $\left[F(10,246)=3.39, p=.000\right.$; Pillai's Trace $=.13$; partial $\left.\eta^{2}=.13\right]$. 
To reduce the chance of a Type 1 error in case of data violation, Pallant (2007) suggests setting a higher alpha level by conducting a Bonferroni adjustment. As there are ten dependent variables to investigate, therefore, the conventional significance value of .05 is divided by 10, giving a new alpha level of .005 . The MANOVA results presented in Table 12 shows the impacts that reached statistical significance when the results for the dependent variables were considered separately.

Table 12. Tests Results for Between-Subjects Effects

\begin{tabular}{llllllll}
\hline Source & Dependent Variable & $\begin{array}{l}\text { Type III Sum } \\
\text { of Squares }\end{array}$ & df & $\begin{array}{l}\text { Mean } \\
\text { Square }\end{array}$ & F & Sig. & $\begin{array}{l}\text { Partial } \\
\eta^{2}\end{array}$ \\
\hline Gender & $\begin{array}{l}\text { How often did you } \\
\text { bully another student or } \\
\text { group of students }\end{array}$ & 1.13 & 1 & 1.13 & 9.02 & .003 & .034 \\
& $\begin{array}{l}\text { I was bullied in these } \\
\text { ways by someone or } \\
\text { people I know }\end{array}$ & 1.58 & 1 & 1.58 & 12.92 & .000 & .048 \\
\cline { 2 - 4 } & $\begin{array}{l}\text { How often did you see } \\
\text { Interment } \\
\text { Access } \\
\text { bully others online? }\end{array}$ & 7.96 & 1 & 7.96 & 11.56 & .001 & .043 \\
\hline
\end{tabular}

As shown in the previous table, gender showed a statistically significant impact on how often students did bully another student or group of students $\left[F(1,287)=9.02, p=.003\right.$, partial $\left.\eta^{2}=.034\right]$. An examination of the mean scores indicated that male students were more involved in activities related to cyberbullying $(M=1.36)$ compared with female students $(M=1.15)$.

Furthermore, single students were found to significantly encounter cyberbullying by someone or people they know $\left[F(1,287)=12.92, p=.000\right.$, partial $\left.\eta^{2}=.048\right]$. An examination of the mean scores indicated that single students face this problem $(M=1.36)$ more than married students $(M=1.24)$.

Finally, having a personal device to access the Internet significantly impacts on how often students see a student or students bully others $\left[F(1,287)=11.56, p=.001\right.$, partial $\left.\eta^{2}=.043\right]$. The mean differences show that students using their own devices tend to observe cyberbullying activities $(M=2.20)$ more compared with those using shared devices $(M=1.64)$.

\section{Discussion}

The descriptive results indicated that students mainly avoid cyberbullying. However, $26.5 \%$ of the students reported that they have bullied other students online once or twice. Furthermore, the majority of the students $(57 \%)$ observed at least one student being cyberbullied once or twice. This result shows that cyberbullying rate in Saudi Arabia has increased compared with Reuters global report in 2012 , from $18 \%$ to about $27 \%$. The increase in cyberbullying rate might indicate a serious prevailing problem and requires further action, despite the fact that these rates are still among the lowest rates globally. This increase can be attributed to the increases in ICT use such as social networking among teenagers and students globally (Couvillon \& Ilieva, 2011; Cowie \& Colliety, 2010; Hinduja \& Patchin, 2010; Gross \& Juvonen, 2008; Hoff \& Mitchell, 2009; Smith \& Yoon, 2012; Tettegah et al., 2006).

Cyberbullied students usually encounter this problem by someone or people who do not know and who contacted them over the Internet. It seems unlikely for students to be cyberbullied by people whom they met over the Internet or by people who know them in reality. This result agrees with existing literature that considers anonymity as an 'encouraging' factor for cyberbullies to target victims of any age (Akbulut \& Eristi, 2011; Grigg, 2012).

While students in the current study perceive cyberbullying as a serious issue, the result comes in line with the current literature that consider cyberbullying as a global concern and can be a real risk to students and may cause them both emotional and physical harm (Akbulut \& Eristi, 2011; Gross \& Juvonen, 2008; Smith \& Yoon, 2012; The Department of Education and Early Childhood Development, 2013). However, these results contradict the findings from the study of Smith and Yoon (2012) who found that the majority of participants did not consider cyberbullying as a problem at the university level. This contradiction can be attributed to the increasing awareness globally about cyberbullying and its negative consequences (Akbulut \& Eristi, 2011; Gross \& Juvonen, 2008; Smith \& Yoon, 2012; The Department of Education and Early Childhood Development, 2013). 
With regard to the students' reactions toward cyberbullying, the students seem to prefer asking cyberbullies to stop, but avoiding fighting back. This result suggests that students in the current study do not prefer the avoidance strategy and differs from the participants in the study of Hoff and Mitchell (2009) as well as Gross and Juvonen (2008). However, in the current study, violence was not an option for students to stop cyberbullying. Rather, actions to stop cyberbullying from the students' perspective includes keeping a record of nasty emails or text messages, neglecting threatening emails or electronic messages, and asking for help from trusted people or authorities in charge such as the police. Hence, while the students prefer to take the responsibility of confronting cyberbullying, necessary action or guidance from universities and other parties such as administrators and social communities seem absent (Hoff $\&$ Mitchell, 2009).

Further statistics show that gender impact on how often students committed cyberbullying. Male students were involved in cyberbullying more than female students. Similarly, Akbulut and Eristi (2011) found that male students were more likely to be cyberbullies. Furthermore, Akbulut and Eristi (2011) revealed some results that agree with the current study. In particular, there was no connection between cyberbullying and socioeconomic status and the place used to access the Internet.

In addition, single students were found to encounter cyberbullying by someone or people they know more than married students. It seems here that relationships are involved. Hoff and Mitchell (2009) found that cyberbullying is most likely to occur from relationship problems such as break-ups, envy, intolerance, and ganging up. These traits are more consistent with single students who are more likely to engage in random relationships or who are trying to make new friends than married students who tend to commit to their partners and friends.

Finally, students having personal devices to access the Internet observe students bully others online more than those using shared devices. It seems logical that students with personal devices to access the Internet see more incidents related to cyberbullying. Those with personal devices have more time, flexibility, and tolerance to access the Internet $24 / 7$ and be involved in cyber-communities than those accessing the Internet via shared devices.

\section{Study Limitations and Further Research}

It is important to report on the major limitations of the current study. This is to provide information on the research context or scope and to give insights for further research. First, the current study was conducted in Saudi Arabia that is a developing country. Therefore, more studies are required in other developing countries to reflect on the current study findings and to gain a brighter picture of the prevalence of cyberbullying in the context of developing countries.

The current study also involved a relatively small sample. Recruiting larger samples is necessary to increase the credibility of the findings. Such wide-scale research can be conducted by authorities and research centers that are involved in studying social interaction and related phenomena.

Moreover, the present study had a scope on higher education, investigating the prevalence of cyberbullying with some possible impacting factors. More research is needed to confirm the study findings in the context of higher education. In addition, it is necessary to address the problem among teenagers and include a variety of possible factors that may stimulate cyberbullying such as the time spent online and the role of interaction in social media.

Finally, as the current study implemented only a quantitative approach, further research using different types of methodologies are required to address the problem and investigate the impacts of cyberbullying on students' learning and social life.

\section{Conclusions and Implications}

The primary aim of the current study was to understand cyberbullying in Saudi's higher education. In addition, the aim was to identify possible factors that may impact cyberbullying. A quantitative approach was implemented using an online survey questionnaire to answer the research questions.

Based on the study findings and the existing literature in addition to the fact that most of the developing countries such as Saudi Arabia are highly policy-driven, the study suggests that policymakers, educators, and people of authority have a great responsibility in the process of identifying, preventing, and imposing solutions for cyberbullying. There should be clear policies that include precise definition of cyberbullying and its consistent traits as well as options to deal with the problem. These policies likewise should include preventative measures to be incorporated in schools' and universities' systems to lessen the impact of cyberbullying on students' academic 
progress as well as social life.

Appropriate policies should be translated in practical guidelines that can be applied with ease. These guidelines should inform schools and universities with proper literature to educate teachers, faculty, and administrators about what is cyberbullying and how to deal with it. Furthermore, it is suggested that these guidelines consider raising awareness and educating students about cyberbullying and its possible consequences. The appropriate and ethical behavior in online or virtual communities should also be included to enhance the quality of online learning. Moreover, these guidelines should encourage cybervictims to seek help and advice, and to face and help stop cyberbullying with practical steps.

Schools, universities, and communities are required to cooperate with authorities responsible for cyber-safety and cyber-crimes to investigate cyberbullying incidents, to identify possible cyberbullies, and to impose dissuasive punishments. Educational institutions are also required to establish centers for therapy that are equipped with experts to deal with students who have been victimized by cyberbullying. These centers should also provide psychological and educational advice and advocate scientific solutions to ensure the well-being of students and their effective learning in the digital era.

\section{References}

Ahlfors, R. (2010). Many sources, one theme: Analysis of cyberbullying prevention and intervention websites. Journal of Social Sciences, 6(4), 515-522.

Akbulut, Y., \& Eristi, B. (2011). Cyberbullying and victimisation among Turkish university students. Australasian Journal of Educational Technology, 27(7), 1155-1170.

Atkinson, C., \& Newton, D. (2010). Online behaviors of adolescents: Victims, perpetrators and web 2.0. Journal of Sexual Aggression, 16(1), 107-120.

Bullying Statistics. (2013). Stop Bullying, Harassment, and Anti-Bully in School/Work. Retrieved 22-7, 2014, from http://www.bullyingstatistics.org/content/cyber-bullying.html

Burnham, J. J., Inman, C. T., Ogorchock, H. N., \& Wright, V. H. (2009). Cyberbullying: Using virtual scenarios to educate and raise awareness. Journal of Computing in Teacher Education, 26(1), 35-41.

Couvillon, M. A., \& Ilieva, V. (2011). Recommended practices: A review of school wide preventative programs and strategies on cyberbullying. Preventing School Failure, 55(2), 96-101.

Cowie, H., \& Colliety, P. (2010). Cyberbullying: sanctions or sensitivity? Pastoral Care in Education, 28(4), 261-268. http://dx.doi.org/10.1080/02643944.2010.528017

Cross, D., Shaw, T., Hearn, L., Epstein, M., Monks, H., Lester, L., \& Thomas, L. (2009). Australian Covert Bullying $\begin{array}{llll}\text { Prevalence Study } & \text { (ACBPS). } & \text { Retrieved }\end{array}$ http://www.deewr.gov.au/Schooling/NationalSafeSchools/Pages/research.aspx

Grigg, D. W. (2012). Definitional constructs of cyber-bullying and cyber-aggression from a triangulatory overview: a preliminary study into elements of cyber-bullying. Journal of Aggression, Conflict and Peace Research, 4(4), 202-215. http://dx.doi.org/10.1108/17596591211270699

Gross, E.F., \& Juvonen, J. (2008). Extending the school grounds? - Bullying experiences in cyberspace. Journal of school health, 78(9), 496-505. http://dx.doi.org/10.1111/j.1746-1561.2008.00335.x

Hinduja, S., \& Patchin, J. W. (2010). Bullying, Cyberbullying, and Suicide. Archives of Suicide Research, 14(3), 206-221. http://dx.doi.org/10.1080/13811118.2010.494133

Hinduja, S., \& Patchin, J. W. (2011). Cyberbullying: A Review of the Legal Issues Facing Educators. Preventing School Failure: Alternative Education for Children and Youth, 55(2), 71-78. http://dx.doi.org/10.1080/1045988x.2011.539433

Hinduja, S., \& Patchin, J.W. (2009). Bullying beyond the schoolyard: Preventing and responding to cyberbullying. Thousand Oaks, CA: Corwin Press.

Hoff, D. L., \& Mitchell, S. N. (2009). Cyberbullying: causes, effects, and remedies. Journal of Educational Administration, 47(5), 652-665. http://dx.doi.org/10.1108/09578230910981107

Kowalski, R. M., Limber, S., \& Agatston, P. W. (2012). Cyberbullying: Bullying in the digital age. Chichester, West Sussex, UK: Wiley-Blackwell. 
Mertens, D. M. (2005). Research and evaluation in education and psychology: integrating diversity with quantitative, qualitative, and mixed methods (2nd ed.). Thousand Oaks, Calif., London: Sage Publications.

Pallant, J. F. (2007). SPSS survival manual: A step by step guide to data analysis using SPSS (3rd ed.). Crows Nest, NSW: Allen \& Unwin.

Reuters. (2012). Cyberbullying a problem around the globe: poll. Retrieved June, 30, 2014, from http://www.reuters.com/article/2012/01/11/us-cyberbullying-poll-idUSTRE80A1FX20120111

Sellers, M., Wray, G., Meeker, N., \& Moulton, S. (2009). Cyberbullying in Higher Education. Paper presented at the World Conference on E-Learning in Corporate, Government, Healthcare, and Higher Education 2009, Vancouver, Canada. http://www.editlib.org/p/32807

Shariff, S. (2005). Cyber-dilemmas in the new millennium: School obligations to provide student safety in a virtual school environment. McGill Journal of Education, 40(3), 467-487.

Smith, J. A., \& Yoon, J. (2012). Cyberbullying Presence, Extent, \& Forms in a Midwestern Post-secondary Institution. Paper presented at the Information Systems Educators Conference, New Orleans Louisiana, USA.

Smith, P.K., Mahdavi, J., Carvalho, M., Fisher, S., Russell, S., \& Tippett, N. (2008). Cyberbullying: Its nature and impact in secondary schools. Journal of Child Psychology and Psychiatry, 49(4), 376-385. http://dx.doi.org/10.1111/j.1469-7610.2007.01846.x

Tettegah, S. Y., Betout, D., \& Taylor, K. R. (2006). Cyber-bullying and schools in an electronic era. In S. Tettegah \& R. Hunter (Eds.), Technology and Education: Issues in Administration, Policy, and Applications in K12 schools (pp. 17-28). London: Elsevier.

The Department of Education and Early Childhood Development. (2013, 08 November 2013). Cyberbullying Retrieved 24-9, 2014, from http://www.education.vic.gov.au/about/programs/bullystoppers/Pages/cyberbullying.aspx

Vandebosch, H., \& Van Cleemput, K. (2008). Defining cyberbullying: A qualitative research into the perceptions of youngsters. Cyber Psychology \& Behavior, 11(4), 499-503. http://dx.doi.org/10.1089/cpb.2007.0042

Vandebosch, H., \& Van Cleemput, K. (2009). Cyberbullying among youngsters: profiles of bullies and victims. New Media \& Society, 11(8), 1349-1371. http://dx.doi.org/10.1177/1461444809341263

Wong-Lo, M., \& Bullock, L. M. (2011). Digital Aggression: Cyberworld Meets School Bullies. Preventing School Failure: Alternative Education for Children and Youth, 55(2), 64-70. http://dx.doi.org/10.1080/1045988x.2011.539429 